\title{
Dual-Band Circularly Polarized Stack-Ring Antenna
}

\author{
Youngje Sung*
}

\begin{abstract}
A stack-ring configuration is proposed for designing a dual-band circularly polarized (CP) antenna. Each ring generates different resonant frequencies. A good CP performance at both resonant frequencies is achieved by adjusting the relative distance between the two rings. The two operating bands are separated with a small frequency ratio of 1.07. Measured results show that radiation patterns with good CP characteristics are obtained at the two resonant frequencies.
\end{abstract}

Key Words: CP Antenna, Dual-Band Antenna.

\section{INTRODUCTION}

The ring antenna is very attractive because a ring has a smaller size and larger bandwidth, compared to a microstrip patch antenna. Ring antennas are mainly designed for linear polarization [1]. However, since circularly polarized (CP) antennas can provide a stable signal quality between the transmitting and receiving devices, they are widely used in wireless communication systems [2]. Until now, much research in the open literature has focused on the design of the dual-band CP antenna [35]. Dual-band CP stacked patch antennas with truncated corners on both lower and upper patches were presented for global positioning system (GPS) applications in [3]. In [4], a CP dielectric resonator antenna loaded with a modified circular patch was proposed for dual-band applications. Both antennas in [3, 4] show the frequency ratio of 1.28. A single-feed dual-band CP antenna was achieved by using an asymmetrical U-shaped slot [5].

Many dual-band CP antennas have been studied [6-10]. Recently, the needs for wireless communication systems that require a small frequency ratio have emerged. The design of the dual-band $\mathrm{CP}$ antenna with a small frequency ratio is rather challenging [6, 7], and is still being studied. In [6] and [7], the single-layer dual-band $\mathrm{CP}$ antennas with a small frequency ratio were implemented using the annular patches, cross slot, and asymmetric feed point. The frequency ratios are 1.10 and 1.21, respectively. In [8], the reported antenna achieved dual-band $\mathrm{CP}$ performance using an asymmetric S-slotted patch, where a frequency ratio of $S_{11}(=1.28)$ was reported. In [9], the proposed antenna consists of an inner circular patch and an outer annular ring to generate dual-band operation. $\mathrm{CP}$ performance was achieved by the cross-slot, and a frequency ratio of 1.28 was reported. In [10], the dual-band CP antenna is composed of two elliptical-ring radiating patches and an asymmetric feed. The frequency ratio was 1.10 .

In this article, we propose a new design for a single-feed dual-band CP antenna. This is achieved by designing two square rings that are stacked together. The asymmetry in the structure refers to the relative distance between the two rings. If the relative distance between the two rings is properly selected, the two orthogonal modes of the antenna would be excited with the same amplitude and a $90^{\circ}$ phase difference at both the lower and upper bands. To confirm the characteristics of the dualband $\mathrm{CP}$ antenna, the antenna designed at 2.5 and $2.67 \mathrm{GHz}$ is

Manuscript received April 27, 2018 ; Revised August 20, 2018 ; Accepted October 26, 2018. (ID No. 20180427-035J)

Department of Electronic Engineering, Kyonggi University, Suwon, Korea.

"Corresponding Author: Youngje Sung (e-mail: yjsung@kgu.ac.kr)

This is an Open-Access article distributed under the terms of the Creative Commons Attribution Non-Commercial License (http://creativecommons.org/licenses/by-nc/4.0) which permits unrestricted non-commercial use, distribution, and reproduction in any medium, provided the original work is properly cited.

(c) Copyright The Korean Institute of Electromagnetic Engineering and Science. All Rights Reserved. 
fabricated and measured.

\section{ANTENNA GEOMETRY}

Fig. 1 shows the proposed dual-band CP antenna on a double-layer. The dielectric constant $\varepsilon_{r}=2.2$ and thickness $h=$ $1.574 \mathrm{~mm}$ of the two substrates are used for the proposed design. The size of substrate_2 is same with that of substrate_1. The ground plane size is $70 \mathrm{~mm} \times 70 \mathrm{~mm}$.

The proposed antenna consists of two square rings and a $\mathrm{T}$ shaped feed line. The two (lower and upper) square rings have the outer side length of $L_{1}$ and $L_{2}$ and widths of $w_{1}$ and $w_{2}$. A lower ring is located on the middle layer and an upper ring is located on the top layer. These rings serve as radiating elements. Here, the center position of the lower ring is established as a reference point. It is denoted by $C(0,0)$. The center position of the upper square ring moves from $(0,0)$ to $7 \mathrm{~mm}$ on the $x$-axis and $10 \mathrm{~mm}$ on the $y$-axis. It is denoted by $C^{\prime}(7,10)$. The width $w_{f}$ of the feed line is chosen to be $4.2 \mathrm{~mm}$, which corresponds to the characteristic impedance of $50 \Omega$. Simulation is carried out using IE3D (Mentor Graphics, Wilsonville, OR, USA).

\section{PARAMETER STUDY}

Fig. 2(a) and (b) show the simulated results of the proposed

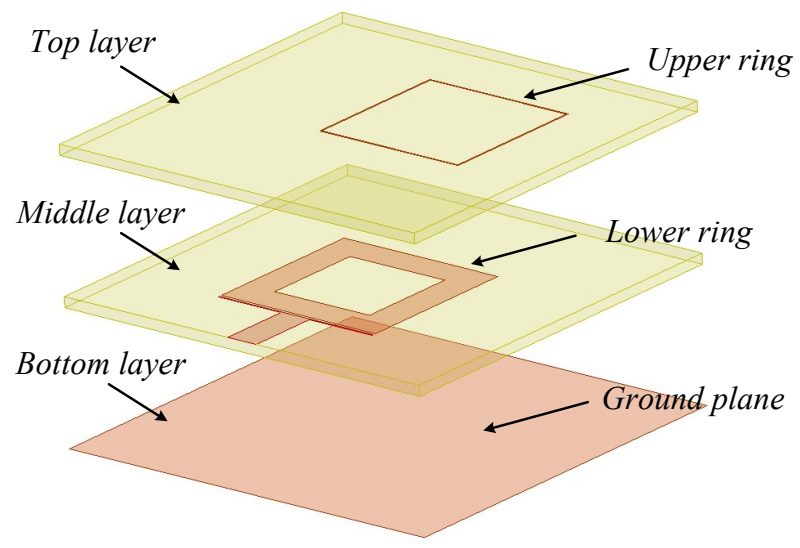

(a)

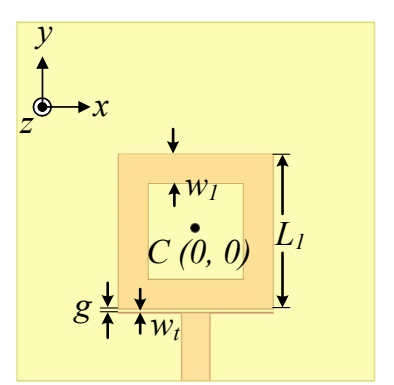

(b)

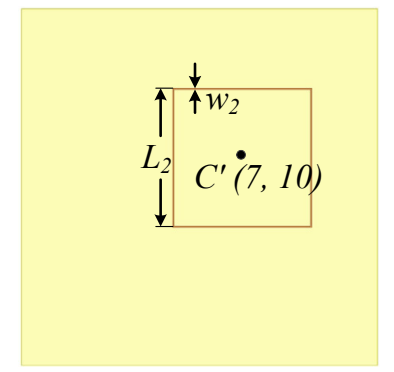

(c)
Fig. 1. Configuration of the proposed structure: (a) 3D view, (b) middle layer, and (c) top layer.

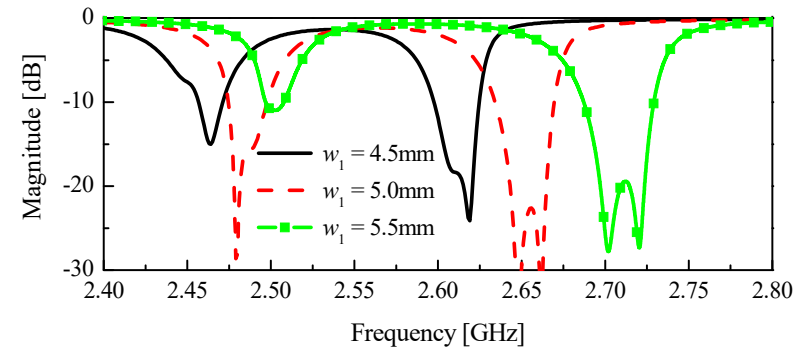

(a)

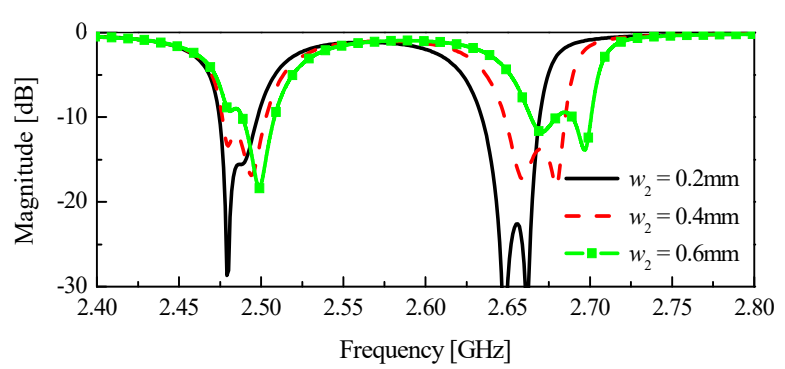

(b)

Fig. 2. Simulated results of the proposed antenna with different widths: (a) $w_{1}$ and (b) $w_{2}$.

antenna for widths $w_{1}$ and $w_{2}$, respectively. The side lengths $\left(L_{1}\right.$ and $L_{2}$ ) of the two square rings are $26 \mathrm{~mm}$ and $23.4 \mathrm{~mm}$, respectively. The other parameters are: $g=0.2 \mathrm{~mm}$ and $w_{t}=0.2$ $\mathrm{mm}$. It is well known that the resonant frequency of the ring resonator is mainly adjusted by changing the width of the ring. In this work, also, the lower ring works as a radiating element and works as a feed structure for the upper ring. Therefore, both resonant frequencies are increased as $w_{1}$ increases. The proposed antenna shows good impedance matching at the upper band when $w_{1}$ are all three values $(4.5 \mathrm{~mm}, 5 \mathrm{~mm}, 5.5 \mathrm{~mm})$ used above. It is observed that impedance matching has the optimum value as the width $w_{1}=5 \mathrm{~mm}$. On the other hand, it can be observed from Fig. 2(b) that an increase in $w_{2}$ increases the upper band. In this case, the lower band remains almost unchanged. Considering the impedance matching characteristic at both bands, the width $w_{2}$ is fixed to $0.2 \mathrm{~mm}$.

Fig. 3 shows the simulated results of the proposed antenna with different positions of the upper ring. In this case, the lower ring is fixed. The other dimensions are the same as before. When the upper ring shifts leftward ( $-x$ axis) or downward $(-y$ axis), there is a greater split between the two degenerated modes at the lower band. On the other hand, the two degenerated modes at the upper band are more split when the upper ring shifts in the opposite direction ( $+x$ axis or $+y$ axis). In the cases of $C^{\prime}(6,10)$ and $C^{\prime}(7,9)$, there is a single resonance at the upper band. Therefore, the proposed antenna exhibits a linear polarization (LP) property at the upper band. In cases of $C^{\prime}(8,10)$ and $C^{\prime}(7,11)$, the proposed antenna shows a single resonance at the lower band. Therefore, the proposed antenna has LP operation 


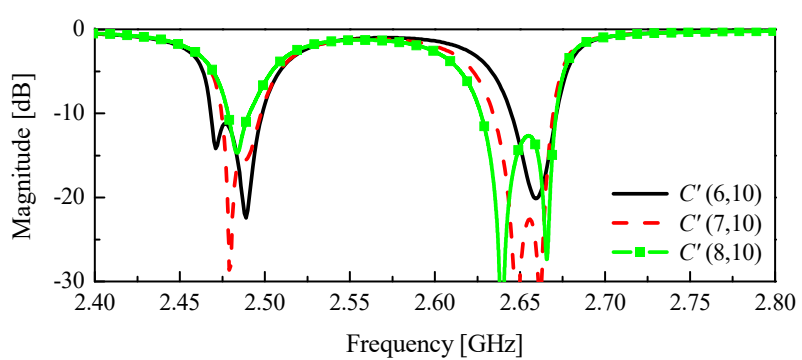

(a)

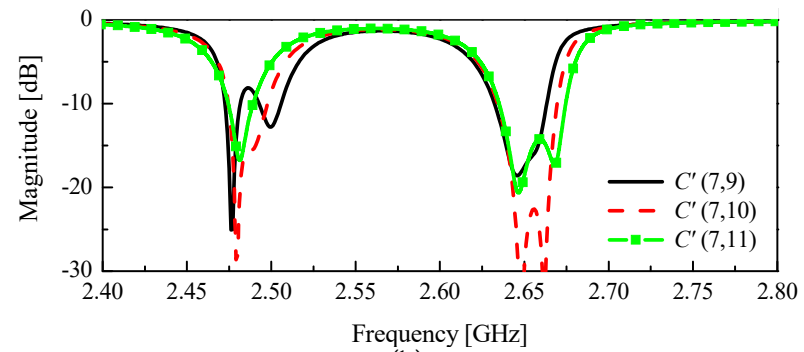

(b)

Fig. 3. Simulated results of the proposed antenna with different positions of the upper ring: (a) $x$ direction shift and (b) $y$ direction shift.

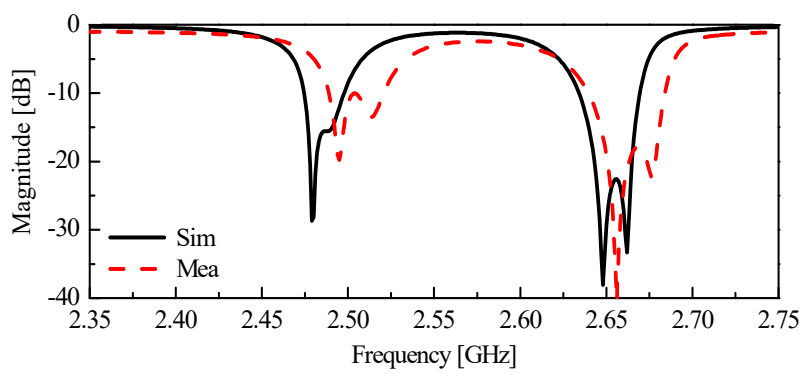

(a)

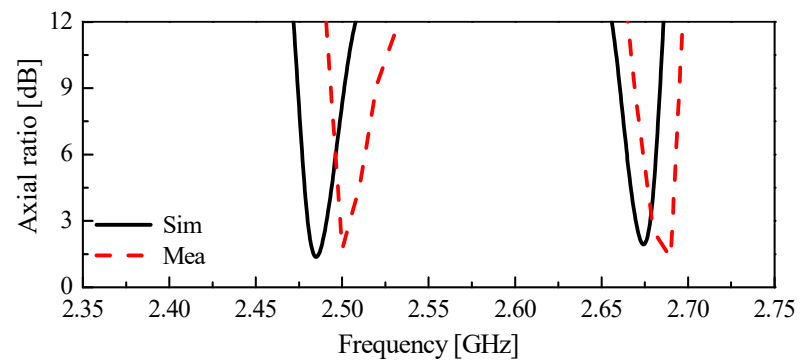

(b)

Fig. 4. Simulated and measured result: (a) reflection coefficient and (b) axial ratio.

at the lower band. With position $C^{\prime}$ chosen to be $(7,10), \mathrm{CP}$ performance has the optimum value in this study.

\section{SimUlated AND MEASURED RESUlTS}

The proposed antenna is designed and fabricated with optimal parameters and measured to confirm the simulation performance. Detailed geometrical parameters of the optimal antenna are as follows: $L_{1}=26 \mathrm{~mm}, L_{2}=23.4 \mathrm{~mm}, w_{1}=5 \mathrm{~mm}$, $w_{2}=0.2 \mathrm{~mm}, g=0.2 \mathrm{~mm}, w_{t}=0.2 \mathrm{~mm}$, and $C^{\prime}(7,10)$. Fig. 4 exhibits both the simulated and measured reflection coefficient and axial-ratio (AR) for the proposed antenna. The proposed antenna features $10-\mathrm{dB}$ impedance bandwidths of $1.3 \%$ and 1.7 $\%$ and $3-\mathrm{dB} A R$ bandwidths of $0.7 \%$ and $0.8 \%$ in the lower and upper bands, respectively. The reason for the difference between measurement and simulation is due to the tiny air gap between the two substrates or the alignment between ring resonators in different layers.

Figs. 5 and 6 show simulated current distributions at 2.482 $\mathrm{GHz}$ and $2.673 \mathrm{GHz}$, respectively. The blue and red areas indicate the minimum and maximum current distributions, respect-

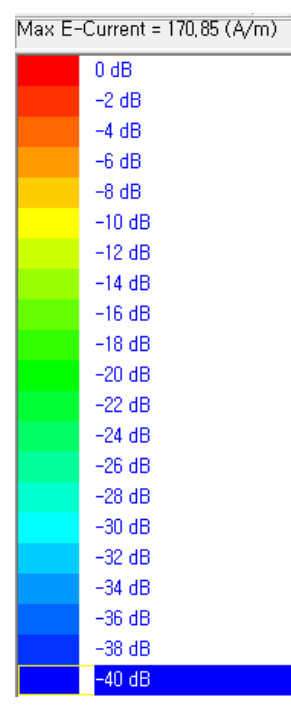

Fig. 5. Simulated current distribution at $2.482 \mathrm{GHz}$ : (a) $0^{\circ}$ and (b) $90^{\circ}$.
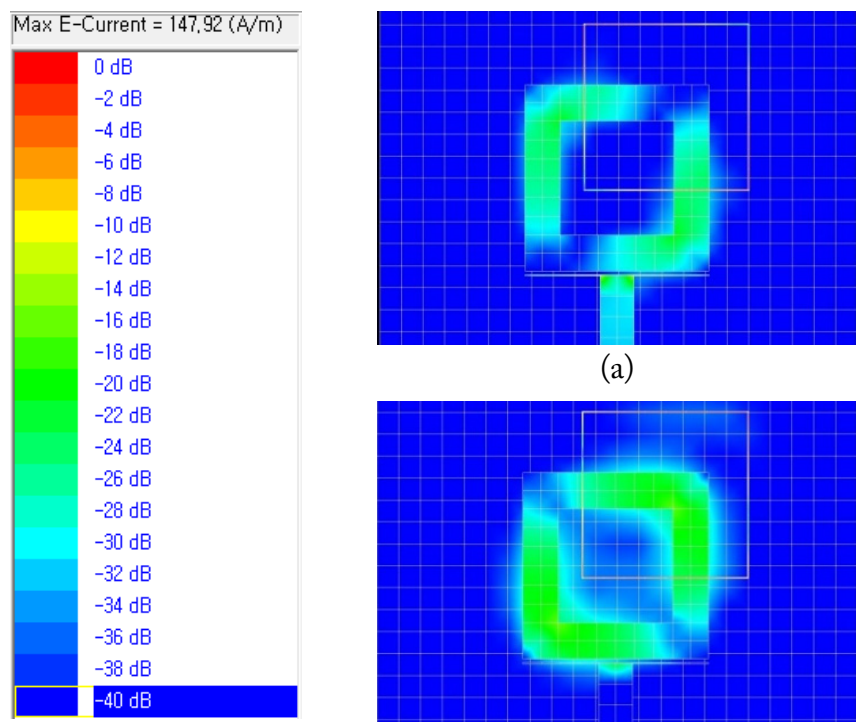

(a)

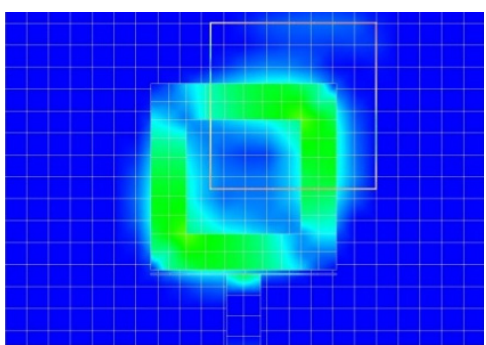

(b)

Fig. 6. Simulated current distribution at $2.673 \mathrm{GHz}$ (a) $0^{\circ}$ and (b) $90^{\circ}$. 


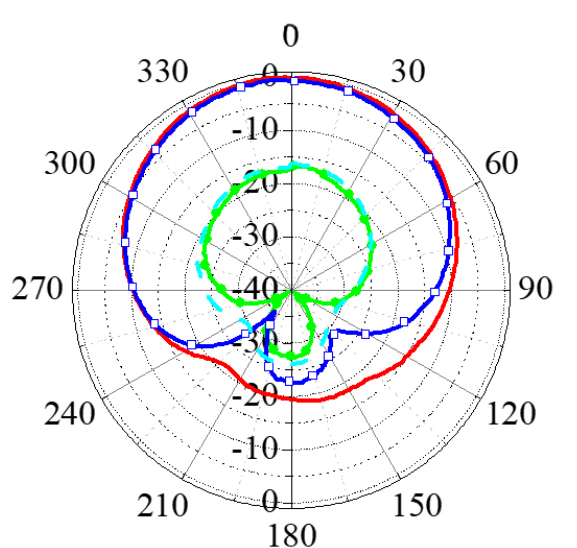

(a)

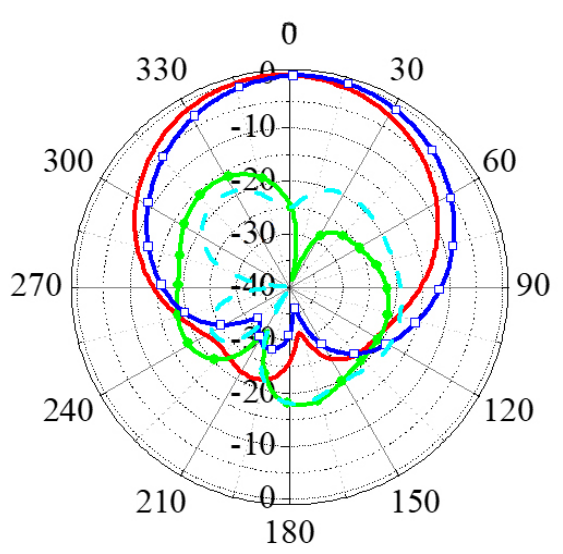

(b)

Fig. 7. Measured radiation pattern: (a) $2.5 \mathrm{GHz}$ and (b) $2.67 \mathrm{GHz}$.

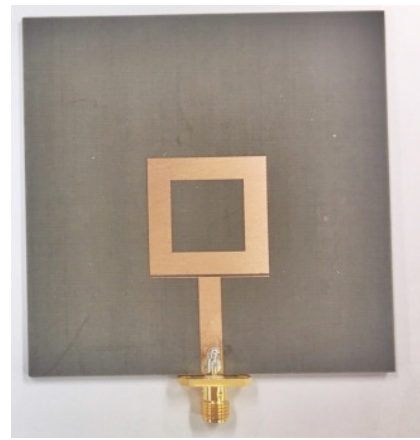

(a)

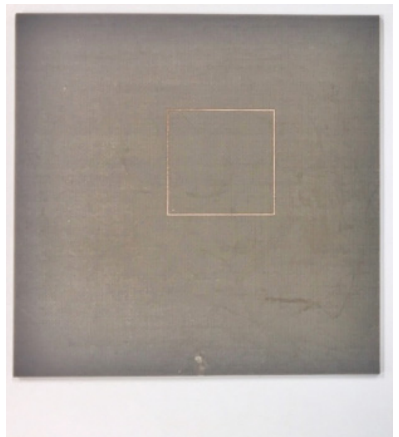

(b)
Fig. 8. Configuration of the proposed structure: (a) middle layer and (b) top layer.

tively. It can be seen from the current distribution that the proposed antenna operates as $\mathrm{CP}$ at two resonant frequencies.

The radiation patterns measured at $2.5 \mathrm{GHz}$ and $2.67 \mathrm{GHz}$ are shown in Fig. 7. It can be found that the proposed antenna radiates a left-hand circularly polarized (LHCP) wave with cross polarization better than $15 \mathrm{~dB}$ for the lower and upper bands. The measured peak gains are about $4.2 \mathrm{dBi}$ for the lower band and $4.6 \mathrm{dBi}$ for the upper band.

Fig. 8 shows the fabricated antenna.

\section{CONCLUSION}

The antenna structure consists of two square rings and a Tshaped feed line, and the proposed antenna exhibits CP operation because the relative distance between the two rings' centers is used as a perturbation. A prototype of the proposed design has been successfully implemented. If a wireless communication system requires a dual-band $\mathrm{CP}$ property with a unidirectional radiation pattern, the proposed antenna is an option that can be considered because it has a simple configuration and is easy to manufacture.

This work was supported by the National Research Foundation of Korea under Grant no. 2017R1A2B4010393 funded by the Korea government.

\section{REFERENCES}

[1] Y. J. Sung, "Frequency and polarisation reconfigurability from an open-loop square ring antenna," IET Microwaves, Antennas \& Propagation, vol. 6, no. 5, pp. 505-509, 2012.

[2] H. M. Chen, Y. K. Wang, Y. F. Lin, C. Y. Lin, and S. C. Pan, "Microstrip-fed circularly polarized square-ring patch antenna for GPS applications," IEEE Transactions on Antennas and Propagation, vol. 57, no. 4, pp. 1264-1267, 2009.

[3] S. Chen, G. Liu, X. Chen, T. Lin, X. Liu, and Z. Duan, "Compact dual-band GPS microstrip antenna using multilayer LTCC substrate," IEEE Antennas and Wireless Propagation Letters, vol. 9, pp. 421-423, 2010.

[4] Y. M. Pan, S. Y. Zheng, and W. Li, "Dual-band and dualsense omnidirectional circularly polarized antenna," IEEE Antennas and Wireless Propagation Letters, vol. 13, pp. 706709, 2014.

[5] P. Nayeri, K. F. Lee, A. Z. Elsherbeni, and F. Yang, "Dualband circularly polarized antennas using stacked patches with asymmetric U-slots," IEEE Antennas and Wireless Propagation Letters, vol. 10, pp. 492-495, 2011.

[6] W. Liao and Q. X. Chu, "Dual-band circularly polarized microstrip antenna with small frequency ratio," Progress In Electromagnetics Research, vol. 15, pp. 145-152, 2010.

[7] X. L. Bao and M. J. Ammann, "Dual-frequency circularlypolarized patch antenna with compact size and small frequency ratio," IEEE Transactions on Antennas and Propagation, vol. 55, no. 7, pp. 2104-2107, 2007.

[8] Z. N. Chen and X. Qing, "Dual-band circularly polarized S-shaped slotted patch antenna with a small frequencyratio," IEEE Transactions on Antennas and Propagation, vol. 58, no. 6, pp. 2112-2115, 2010.

[9] N. Pham, J. Y. Chung, and B. Lee, "A proximity-fed antenna for dual-band GPS receiver," Progress In Electromag- 
netics Research, vol. 61, pp. 1-8, 2016.

[10] Z. Wang, R. She, J. Han, S. Fang, and Y. Liu, "Dual-band dual-sense circularly polarized stacked patch antenna with a small frequency ratio for UHF RFID reader applications," IEEE Access, vol. 5, pp. 15260-15270, 2017.

\section{Youngje Sung}

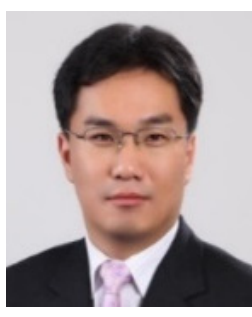

He received his B.S., M.S., and Ph.D. degrees from Korea University, Seoul, Korea, in 2001, 2002, and 2005, respectively. From 2005 to 2008, he was a senior engineer at the Antenna R\&D Laboratory, Mobile Phone Division, Samsung Electronics, Korea. In 2008, he joined the Department of Electronic Engineering, Kyonggi University, Suwon, Korea, where he is currently a professor. His research interests include reconfigurable antennas, cellphone antennas, wideband slot antennas, multifunction devices, compact circular polarized antennas, and compact dual-mode filters. Prof. Sung serves as a reviewer for IEEE Transactions on Microwave Theory and Techniques, IEEE Transactions on Antennas and Propagation, IEEE Microwave and Wireless Components Letters, IEEE Antennas and Wireless Propagation Letters, Progress in Electromagnetic Research, IET Electronics Letters, and IET Microwaves, Antennas, and Propagation. 